\title{
A case series of an off-the-shelf online health resource with integrated nurse coaching to support self-management in COPD
}

This article was published in the following Dove Press journal:

International Journal of COPD

9 October 2017

Number of times this article has been viewed

\author{
Frances Early' \\ Jane S Young ${ }^{2}$ \\ Elizabeth Robinshaw ${ }^{3}$ \\ Emma Z Mi ${ }^{4}$ \\ Ella $\mathrm{Z} \mathrm{Mi}{ }^{4}$ \\ Jonathan P Fuld'
}

'Centre for Self Management Support, Cambridge University Hospitals NHS Foundation Trust, Cambridge, UK; ${ }^{2}$ Faculty of Health, Social Care and Education, School of Nursing and Midwifery, Anglia Ruskin University, Cambridge, UK; ${ }^{3}$ Gloucestershire Hospitals NHS Foundation Trust, Gloucester, UK; ${ }^{4}$ School of Clinical Medicine, University of Cambridge, Cambridge, UK
Correspondence: Frances Early Box 146, Cambridge University Hospitals NHS Foundation Trust, Hills Road, Cambridge CB2 0QQ, UK

Tel +44 I223245 I5।

Email frances.early@addenbrookes.nhs.uk
Background: COPD has significant psychosocial impact. Self-management support improves quality of life, but programs are not universally available. IT-based self-management interventions can provide home-based support, but have mixed results. We conducted a case series of an off-theshelf Internet-based health-promotion program, The Preventive Plan (TPP), coupled with nursecoach support, which aimed to increase patient activation and provide self-management benefits. Materials and methods: A total of 19 COPD patients were recruited, and 14 completed 3-month follow-up in two groups: groups 1 and 2 with more and less advanced COPD, respectively. Change in patient activation was determined with paired $t$-tests and Wilcoxon signed-rank tests. Benefits and user experience were explored in semistructured interviews, analyzed thematically.

Results: Only group 1 improved significantly in activation, from a lower baseline than group 2; group 1 also improved significantly in mastery and anxiety. Both groups felt significantly more informed about COPD and reported physical functioning improvements. Group 1 reported improvements in mood and confidence. Overall, group 2 reported fewer benefits than group 1. Both groups valued nurse-coach support; for group 1, it was more important than TPP in building confidence to self-manage. The design of TPP and lack of motivation to use IT were barriers to use, but disease severity and poor IT skills were not.

Discussion: Our findings demonstrate the feasibility of combining nurse-coach support aligned to an Internet-based health resource, TPP, in COPD and provide learning about the challenges of such an approach and the importance of the nurse-coach role.

Keywords: COPD, self-management, Internet, coaching, patient activation

\section{Plain-language summary}

An important part of managing COPD is self-management by the patient. With IT-based self-management programs, patients can do this from their own home, which is easier for them and more cost-effective for the health care provider. Our goal was to explore how a generic Internet-based health-promotion program, The Preventive Plan (TPP), containing programs to support behavior change and health information, combined with support from a specialist nurse, could help patients to manage their COPD. We collected data from and interviewed 19 patients. We found that TPP and nurse support improved patient activation (the belief that one has a role in self-managing care and possession of knowledge and skills to do so), physical function, mood and confidence, and reduced patients' information needs. Patients with more severe COPD gained the most benefit. Support from the nurse was considered to be more important than the Internet-based program by those with more severe COPD, and lack of motivation to use IT was a barrier to use, but poor IT skills and disease severity were not. Our findings demonstrate that a low-intensity intervention can produce meaningful benefits, and provides 
learning about the challenges of this approach and the importance of the nurse coach role.

\section{Introduction}

COPD is a progressive lung disease causing breathlessness, cough, fatigue, reduced exercise capacity, and frequent infections, with high societal burden. ${ }^{1}$ Medication optimizes airway function and reduces symptoms, but cannot address the psychosocial impact of the disease, including anxiety and depression, ${ }^{2}$ social isolation, and loss of independence and self-esteem. ${ }^{3}$

Self-management support interventions in COPD have been shown to improve health-related quality of life, ${ }^{4,5}$ exercise capacity, ${ }^{5}$ and self-efficacy ${ }^{5}$ and reduce COPDrelated hospital admissions. ${ }^{4}$ However, for those unable or unwilling to attend group classes, IT-based approaches can provide support. $^{6-11}$ IT-based self-management and lifestylechange interventions for COPD have reported improved health-related quality of life, ${ }^{9,12-16}$ physical activity, ${ }^{13,14,17}$ exercise capacity, ${ }^{12,16}$ and functional capacity ${ }^{18,19}$ and reduced number and duration of hospital admissions..$^{9,18,20-23}$ Participants have shown improved knowledge and awareness of their symptoms and health status, ${ }^{19,24}$ and qualitative analyses indicate positive effects on self-management, psychological condition, and coping ability. ${ }^{18,25}$ However, other studies have failed to detect positive changes in quality of life, ${ }^{7,17,22}$ smoking cessation, ${ }^{6}$ physical activity, ${ }^{6,711}$ or dyspnea, ${ }^{6,7,11,14}$ and results for self-efficacy are mixed, ${ }^{7,17,25}$ which may reflect heterogeneity among interventions: some were complemented with nurse or allied health-professional support, ${ }^{7,8,15-18,20,22}$ while others offered a stand-alone technological platform. . $^{6,12-14,21,24,26}$

Patient activation is the belief that one has a role in selfmanaging care and the possession of knowledge and skills to manage one's condition, maintain functioning, collaborate with health care providers, and access appropriate care. ${ }^{27}$ Activation impacts on health behavior, clinical outcomes, health care costs, and patient experiences. ${ }^{28}$ However, little is known about the impact of IT-based interventions on patient activation in COPD.

Using a case-series design, we explored the feasibility of an off-the-shelf Internet-based health-promotion program, the Preventive Plan (TPP), coupled with nurse-coach support for home-based self-management of COPD with a focus on patient activation. We also aimed to identify patientreported self-management benefits and factors influencing self-management goal achievement, and to generate generic learning to benefit users of ehealth interventions.

\section{Materials and methods Participants}

Patients were recruited between May 2012 and January 2013. Inclusion criteria at the outset were: COPD diagnosis (forced expiratory volume in 1 second $\left[\mathrm{FEV}_{1}\right]$ /forced vital capacity $[\mathrm{FVC}]<0.7$ ), $\mathrm{FEV}_{1}<50 \%$ predicted (GOLD stage 3 and 4 ), two or more COPD exacerbation-related hospital admissions within the last year, had not attended pulmonary rehabilitation within the last year, and age $>18$ years. Exclusion criteria were diagnosis of lung cancer within the last year and being under the care of a psychologist for management of anxiety/depression. Eleven patients fulfilling these criteria were recruited (group 1). It was challenging to engage patients who met these criteria, and so to increase the number of participants, we adjusted the inclusion criteria for a second group (group 2) to include: $\mathrm{FEV}_{1}<80 \%$ predicted (GOLD stage 2-4) and troubled by breathlessness. We imposed no restriction on the number of exacerbation-related hospital admissions for this group. This enabled us to recruit a further eight patients.

\section{Design}

This case series employed mixed methods of quantitative outcome assessment and qualitative interviews. The intervention comprised an off-the-shelf Internet-based program, TPP, and nurse-coach support. TPP encompassed primary prevention, secondary prevention, and chronic-condition management. It was a generic tool personalized by uploading personal details, completing a health-risk assessment, and generation of a personalized prevention plan. Users accessed health-information resources and action programs to support behavior change. There was a messaging facility for email contact with the nurse. TPP could be accessed ad libitum by participants. The nurse coach (same for all participants) was a respiratory nurse specialist. She was trained to use TPP by the application developers and received training from a clinical communication skills specialist to use a coproduction consultation model to support self-management. ${ }^{29}$ Through home visits, telephone, and email she provided self-management support, disease education, assisted participants to use TPP and IT hardware, and "signposted" complementary selfmanagement and COPD-specific resources (Supplementary material). For group 2, she added further disease-specific content through weekly emails of material that replicated the educational content of pulmonary rehabilitation. This addition was made in the context of a pragmatic exploration of how the online platform could be built on for the benefit of patients. We provided laptop computers and Internet 
connectivity for patients with no existing access. No changes were made to participants' usual care.

\section{Data collection}

Baseline measures, including spirometry, were collected by the nurse. Outcomes were measured at 3-month follow-up. Patient activation for self-management was assessed by the Patient Activation Measure. ${ }^{30}$ Scores of $0-100$ represent four activation levels:

- level $1(<47)$ - disengaged, overwhelmed, and may not believe patient role is important

- level 2 (47.1-55.1) - becoming aware, but lacks confidence and knowledge

- level 3 (55.2-67) - beginning to take action

- level 4 (>67.1) - making changes, but may have difficulty maintaining behaviors over time.

We also assessed patient health-related quality of life using the Chronic Respiratory Questionnaire (CRQ), ${ }^{31}$ anxiety and depression using the Hospital Anxiety and Depression Scale (HADS), ${ }^{32}$ and information needs using the Lung Information Needs Questionnaire (LINQ). ${ }^{33}$

All participants were interviewed by $\mathrm{KH}$ at 1 month after baseline to explore interim progress and at 3-month follow-up. Semistructured interviews explored participants' self-management aims, benefits achieved, and challenges or enablers to achieving their self-management goals (Table S1). Website activity was logged and time-stamped to identify the number of days on which participants logged in and the number of pages loaded. The nurse recorded the number and duration of contacts by email, phone, and home visit.

\section{Data analysis}

Baseline characteristics for groups 1 and 2 were compared using Fisher's exact, independent $t$-, and Mann-Whitney $U$ tests. Baseline and follow-up outcome data for each group (14 patients in total) were analyzed with paired $t$ - and Wilcoxon signed-rank tests. Statistical significance was set at $P \leq 0.05$. All statistical analysis was performed in SPSS version 23 (IBM, Armonk, NY, USA).

Transcribed interviews were imported into NVivo software and analyzed thematically. ${ }^{34}$ Transcripts were initially read by FE to gain an overview of patients' experiences. A deductive coding framework was developed by FE, consisting of codes from the interview-topic areas, and transcripts were coded by FE and ER. During coding, deductive codes were supplemented by inductive codes to capture unexpected findings. Codes were checked for duplication and redundancy and organized into categories. Categories were compared across transcripts and between the groups and summarized in matrices, on which the final interpretation was based.

\section{Ethical considerations}

This case series was categorized as a service evaluation by the Research and Development Department at Cambridge University Hospitals NHS Foundation Trust and was subsequently approved and registered as a service evaluation with the Safety and Quality Support Department at the same trust (project registration 570). Patients gave written informed consent to participate in the study to the nurse coach at the first visit. Specific written consent to participate in qualitative interviews was taken by $\mathrm{KH}$ at the beginning of the first interview.

\section{Results}

\section{Participants}

A total of 46 patients were invited and 19 responded (eleven in group 1 and eight in group 2) (Figure 1). Commonest reasons for declining were not wishing to use the Internet and not needing help. A total of 14 patients completed 3-month follow-up (eight in group 1 and six in group 2). Patients lost to follow-up were older (mean $73.2 \pm 11.84$ vs $60.64 \pm 9.44$ years, $P=0.028$ ), but did not differ on any other baseline characteristic. Nine patients from group 1 and six from group 2 were interviewed, with interviews lasting 20-58 minutes.

\section{Baseline characteristics}

Several indicators of disease severity were more severe in group 1 compared to group 2: lower $\mathrm{FEV}_{1}, \mathrm{FEV}_{1} \%$ predicted and $\mathrm{FEV}_{1} / \mathrm{FVC}$, and higher GOLD stage, Medical Research Council dyspnea scale, supplementary oxygen use, and hospital admissions in the previous year (Table 1). The mean number of exacerbations in the past year for group 2 was seven, higher than for group 1, despite few hospital admissions. These were self-reported exacerbations that required antibiotics or steroid use for worsening symptoms, and the data for group 2 were skewed by two patients who had 20 and 14 exacerbations (but only zero and one hospital admissions, respectively).

\section{Patient activation}

Fourteen patients provided baseline and follow-up data (Table 2). Baseline activation scores were significantly lower $(P=0.043)$ for group $1(51.98 \pm 7.36)$ than group 2 (61.22 \pm 7.9). At follow-up, group 1 showed a significant increase $(P=0.022)$ in activation from level $2(51.98 \pm 7.36)$ to 3 (64.11 \pm 8.09$)$. Group 2 increased insignificantly $(P=0.111)$ from level $3(61.22 \pm 7.89)$ to $4(72.73 \pm 16.11)$. 


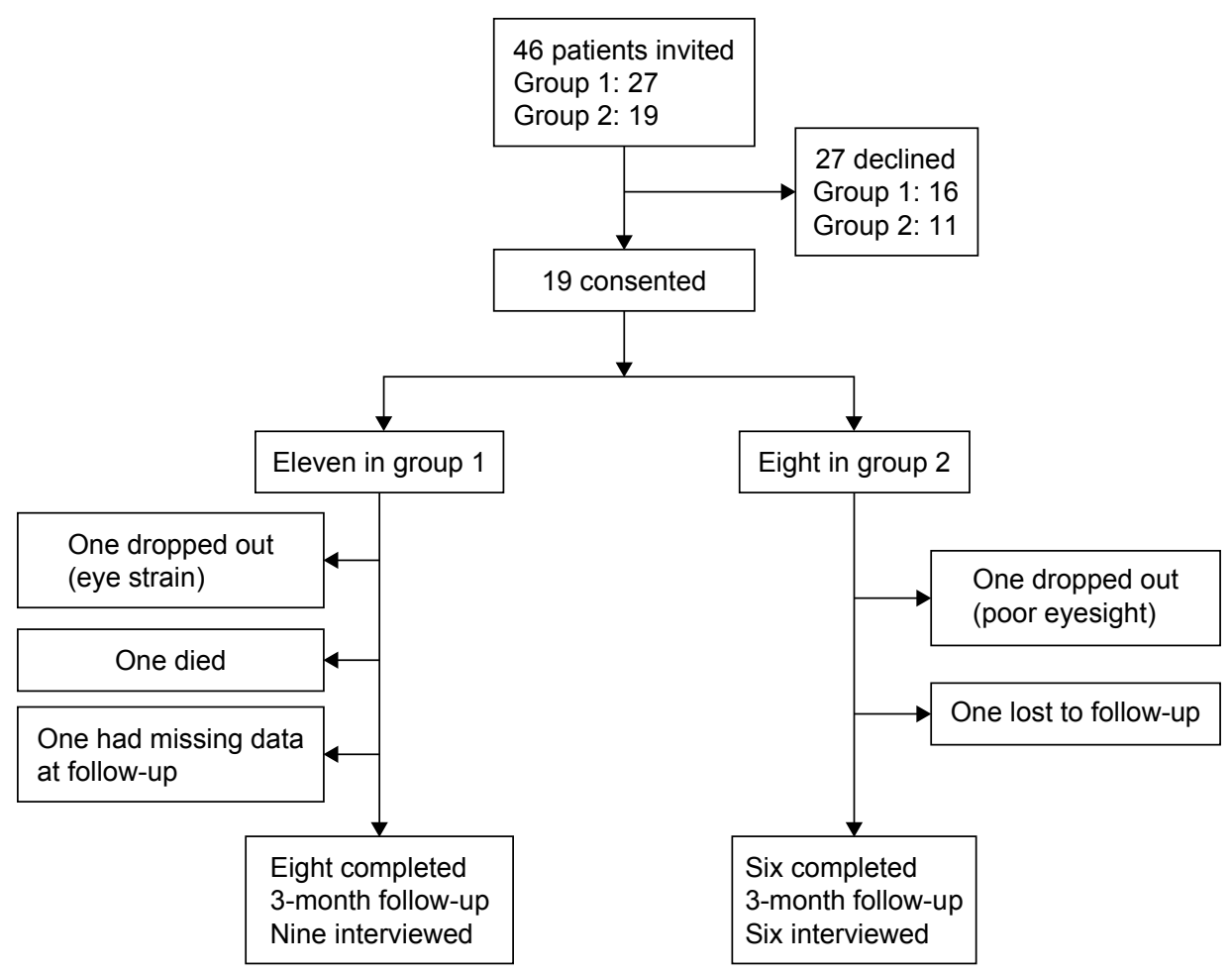

Figure I Study participants.

\section{Other outcomes}

The only significant difference at baseline between groups 1 and 2 was in mastery (mean $3.44 \pm 1.38$ vs $5.17 \pm 0.61$, $P=0.015$ ). At follow-up, group 1 showed a clinically meaningful and statistically significant improvement in mastery (mean $3.44 \pm 1.38$ to $4.38 \pm 1.4, P=0.04$ ) and improvement in anxiety (mean $11.38 \pm 3.81$ to $8.88 \pm 4.32, P=0.028$ ). Both groups had reduced information needs (group 1, median [IQR] 5.5 [4.25-6] to 3 [1.25-3.75], $P=0.008$; group 2, 5.5 [2.26] to 3.33 [1.75], $P=0.027$ ).

\section{Interview data}

Tables 3 and 4 describe the categories into which the codes were organized. In some cases, common category headings apply across both groups, but the way in which the category is manifested differs between the groups.

\section{Aims}

Both groups wished to improve their physical functioning and better manage their health and COPD (Table 3). In this regard, group 1 were focused on getting fitter and staying out of hospital, while group 2, with less severe COPD, focused on daily activities and slowing COPD progression. Group 1 also wanted more independence, and group 2 wanted increased motivation.

\section{Benefits}

Both groups benefited from improved physical functioning (Table 3). For group 1 this was the most commonly reported benefit and enabled more independence. Both groups felt better able to manage their COPD and gained understanding of healthy behaviors, such as healthy eating. Social and emotional functioning improved for both groups. While group 2 gained in self-belief, for group 1 the benefits were wider-ranging, including being able to connect better with others and improved mood and confidence:

I felt good enough to get out the door under me own steam, carrying my oxygen ... I walked round the garden ... feeling normal for, you know, it could be years actually.

\section{[115, group 1]}

Some in group 2 benefited from being able to communicate better with health care professionals. One patient was able to be more assertive in explaining why they wanted a hospital referral, and this helped them to get the referral they had long wanted:

I've never been referred to the hospital, so [nurse coach] said, "What's your goal?" Well, I went to [the doctor] and said, "I feel different and I want to know if there's anything else going on", so he sent me for chest X-rays ... and took my blood ... He phoned up [community respiratory nurse] 
Table I Participant characteristics at baseline

\begin{tabular}{|c|c|c|c|c|}
\hline & Group I $(n=I I)$ & Group $2(n=8)$ & Statistic & $P$-value \\
\hline Age, mean (SD) & $66.36(12.33)$ & $60.63(9.47)$ & $t=1.099$ & 0.287 \\
\hline \multicolumn{5}{|l|}{ Sex, n (\%) } \\
\hline Male & $6(54.55)$ & $3(37.5)$ & & \multirow[t]{2}{*}{0.65} \\
\hline Female & $5(45.45)$ & $5(62.5)$ & & \\
\hline Educational level, median (IQR)a & $I(I-I)$ & $I(I-I)$ & $U=43$ & 1 \\
\hline \multicolumn{5}{|l|}{ Employment, n (\%) } \\
\hline Employed & 0 & I (I2.5) & & \multirow[t]{2}{*}{0.421} \\
\hline Unemployed/retired & II (I00) & 7 (87.5) & & \\
\hline \multicolumn{5}{|l|}{ Living arrangements, n (\%) } \\
\hline Alone & I (9.09) & $3(37.5)$ & & \multirow[t]{2}{*}{0.262} \\
\hline With others & $10(90.91)$ & $5(62.5)$ & & \\
\hline \multicolumn{5}{|l|}{ Current smoking, n (\%) } \\
\hline Yes & $3(27.27)$ & $5(62.5)$ & & \multirow[t]{2}{*}{0.181} \\
\hline No & $8(72.73)$ & $3(37.5)$ & & \\
\hline Pack-years, median (IQR) & $40(33-80)$ & $40(16.5-49.1)$ & $U=36$ & 0.527 \\
\hline \multicolumn{5}{|l|}{ Disease severity } \\
\hline $\mathrm{FEV}_{1}(\mathrm{~L})$, mean $(\mathrm{SD})$ & $0.72(0.25)$ & $1.36(0.67)$ & $t=-2.56 \mathrm{I}$ & $0.032 *$ \\
\hline $\mathrm{FEV}$,\% predicted, median (IQR) & $25.4(18.4-36.2)$ & $48.2(33-64.8)$ & $U=12$ & $0.006 *$ \\
\hline $\mathrm{FEV}_{1} / \mathrm{FVC}$, median (IQR) & $0.31(0.27-0.43)$ & $0.54(0.4-0.68)$ & $U=16.5$ & $0.022^{*}$ \\
\hline GOLD stage, median (IQR) & $4(3-4)$ & $2.5(2-3)$ & $U=22.5$ & $0.046 *$ \\
\hline GOLD ABCD classification, median & $\mathrm{D}$ & $\mathrm{D}$ & & 0.421 \\
\hline MRC dyspnea scale, median (IQR) & $5(4-5)$ & $4(4-4)$ & $U=17.5$ & $0.012 *$ \\
\hline \multicolumn{5}{|l|}{ Supplemental oxygen, n (\%) } \\
\hline Yes & $5(45.45)$ & 0 & & \multirow[t]{2}{*}{$0.045^{*}$} \\
\hline No & $6(54.55)$ & $8(100)$ & & \\
\hline Duration of COPD, median (IQR) & $10.3(7.39)$ & $6.43(3.91)$ & $t=1.259$ & 0.227 \\
\hline Exacerbations in past year, mean (SD) & $3.7(2.75)$ & $7(6.78)$ & $t=-1.409$ & 0.178 \\
\hline Hospital admissions in past year, median (IQR) & $4(2-6)$ & $0(0-0.75)$ & $U=0$ & $<0.0005^{*}$ \\
\hline A\&E attendances in past year, median (IQR) & $0(0-I)$ & $0(0-0.75)$ & $U=38$ & 0.716 \\
\hline \multicolumn{5}{|l|}{ Other } \\
\hline Confidence managing COPD, mean (SD) ${ }^{\mathrm{b}}$ & $6.18(1.83)$ & $7.75(1.91)$ & $t=-1.809$ & 0.088 \\
\hline \multicolumn{5}{|l|}{ Previous PR, $n(\%)$} \\
\hline Yes & $7(63.64)$ & $5(62.5)$ & & \multirow[t]{2}{*}{1} \\
\hline No & $4(36.36)$ & $3(37.5)$ & & \\
\hline \multicolumn{5}{|l|}{ Computer/Internet use } \\
\hline \multicolumn{5}{|l|}{ Internet access at home, $\mathrm{n}(\%)$} \\
\hline Yes & $9(81.82)$ & $6(75)$ & & \multirow[t]{2}{*}{1} \\
\hline No & $2(18.18)$ & $2(25)$ & & \\
\hline \multicolumn{5}{|l|}{ Internet user, n (\%) } \\
\hline Yes & $10(90.91)$ & $5(62.5)$ & & \multirow[t]{2}{*}{0.262} \\
\hline No & I (9.09) & $3(37.5)$ & & \\
\hline \multicolumn{5}{|l|}{ Email user, n (\%) } \\
\hline Yes & $5(45.45)$ & $4(50)$ & & \multirow[t]{2}{*}{1} \\
\hline No & $6(54.55)$ & $4(50)$ & & \\
\hline Frequency of use, median (IQR)c & $3(2-4)$ & $2.5(0-4)$ & $U=34$ & 0.425 \\
\hline Confidence using IT, mean (SD) ${ }^{\mathrm{b}}$ & $6.8(2.82)$ & $6.0(3.07)$ & $t=0.575$ & 0.573 \\
\hline
\end{tabular}

Notes: ${ }^{a} 0$ - none, I - secondary education, 2 - college/higher education; ${ }^{b} 0$ - 10 scale; ${ }^{c} 0$ - never, I - occasional, 2 - once a week, 3 - several times a week, 4 - daily. *significant at $P \leq 0.05$.

Abbreviations: FEV , forced expiratory volume in I second; FVC, forced vital capacity; GOLD, Global Initiative for Chronic Obstructive Lung Disease; MRC, Medical Research Council; PR, pulmonary rehabilitation.

and said about referring me to hospital ... I achieved my goals. [122, group 2]

\section{Factors facilitating goal achievement}

Nurse-coach support was important for both groups and the benefits similar, although group 1 derived more in terms of emotional support. For this group, it had a greater impact than TPP (Table 4):

I was getting depressed and down, so [the nurse] ... she suggested about the models ... and that was an ideal thing ... every time she spoke to me by phone or sent me an email 
Table 2 Change in outcome measures

\begin{tabular}{|c|c|c|c|c|c|c|c|c|}
\hline & \multicolumn{4}{|l|}{ Group I $(n=8)$} & \multicolumn{4}{|l|}{ Group $2(n=6)$} \\
\hline & Baseline & Follow-up & Statistic & $P$-value & Baseline & Follow-up & Statistic & $P$-value \\
\hline Patient Activation Measure & $51.98(7.36)$ & $64.11(8.09)$ & $t=-2.939$ & $0.022^{*}$ & $61.22(7.89)$ & $72.73(16.11)$ & $t=-|.93|$ & 0.111 \\
\hline CRQ - dyspnea & $1.8(1.65-2.15)$ & $1.90(1.4-2.75)$ & $W=13$ & 0.906 & $2.8(1.36)$ & $2.93(I .5 I)$ & $t=-0.791$ & 0.465 \\
\hline CRQ - emotion & $3.5 \mathrm{I}(\mathrm{I} .4 \mathrm{I})$ & $4.08(1.53)$ & $t=-1.725$ & 0.128 & $4.65(2.04)$ & $4.15(1.83)$ & $t=1.739$ & 0.143 \\
\hline CRQ - fatigue & $2.13(1.75-3)$ & $2.88(I .8 I-4.5)$ & $W=6$ & 0.133 & $2.25(1.75-3.38)$ & $3.13(1.44-5.31)$ & $W=5.5$ & 0.344 \\
\hline CRQ - mastery & $3.44(1.38)$ & $4.38(1.4)$ & $t=-2.525$ & $0.04 *$ & $5.17(0.61)$ & $4.92(1.47)$ & $t=0.518$ & 0.627 \\
\hline HADS - depression & $8.75(3.69)$ & $7.38(3.42)$ & $t=1.553$ & 0.164 & $5.67(1.86)$ & $6.17(6.08)$ & $t=-0.209$ & 0.843 \\
\hline HADS - anxiety & II.38 (3.8I) & $8.88(4.32)$ & $t=2.758$ & $0.028^{*}$ & $8.83(3.76)$ & $8.33(3.44)$ & $t=0.436$ & 0.681 \\
\hline LINQ & $5.5(4.25-6)$ & $3.00(1.25-3.75)$ & $W=0$ & $0.008 *$ & $5.5(2.26)$ & $3.33(1.75)$ & $t=3.081$ & $0.027^{*}$ \\
\hline
\end{tabular}

Notes: Mean (SD) for all $t$-statistics; medians (IQR) for all W-statistics. *significant at $P \leq 0.05$.

Abbreviations: CRQ, Chronic Respiratory Questionnaire; HADS, Hospital Anxiety and Depression Scale; LINQ, Lung Information Needs Questionnaire.

or come round, she's always asked how it's going with the models. So yeah, that's made a difference. [110, group 1]

The most helpful thing is, like, talking to [the nurse] about different things. Computers don't really answer you back when you ask it a question. [108, group 1]

TPP provided additional support for both groups through information and action plans, eg, healthy eating and smoking cessation, but group 2 found TPP relatively more useful:

[TPP] gives you different ideas, what they class as one serving ... it's made me think about what I'm eating ... I would have just thrown steak into a frying pan ... whereas now I'll grill it. [109, group 2]

Both groups used TPP most frequently to contact the nurse. Other facilitating factors relevant to both groups were social support from family and friends, psychological factors relating to the individual's own feelings of confidence and motivation, and the possession of self-management skills, which in turn were supported by the nurse coach and the use of TPP.

\section{Challenges to achieving goals}

Poor physical well-being affected progress and prevented activity for both groups, but particularly so for group 1

(Table 4):

I've had a couple of chest infections, so I've been finding it quite hard. I've got a DVD that [the nurse] gave me. I haven't been able to get into it because of the last few months. My tummy's quite painful. [101, group 1]

For some in group 1, this reduced their confidence and was compounded by being in hospital. Psychological factors were a challenge for both groups, with anxiety a particular challenge for group 1:

I just get so out of breath that I just sit here because ... I'm scared to get out of breath. Even though I know it's not going to hurt me, it's just very unpleasant. [105, group 1]

Table 3 Aims and benefits

\begin{tabular}{|c|c|c|}
\hline Category & Group I & Group 2 \\
\hline \multicolumn{3}{|l|}{ Aims } \\
\hline Physical functioning & To be physically fitter and more active & $\begin{array}{l}\text { To do more and have more stamina and } \\
\text { a better lifestyle }\end{array}$ \\
\hline Manage health and COPD & $\begin{array}{l}\text { To stay out of hospital and better manage COPD and } \\
\text { infections }\end{array}$ & $\begin{array}{l}\text { To help myself more by preventing } \\
\text { worsening of symptoms and avoiding hospital }\end{array}$ \\
\hline Independence & To be more independent and depend less on family and friends & NA \\
\hline Increase motivation & NA & To gain motivation for more daily activities \\
\hline \multicolumn{3}{|l|}{ Benefits } \\
\hline Physical functioning & $\begin{array}{l}\text { More able to walk, exercise and do household activities; more } \\
\text { energy; able to be more independent }\end{array}$ & More physically able, better sleep \\
\hline $\begin{array}{l}\text { Managing health and } \\
\text { COPD }\end{array}$ & $\begin{array}{l}\text { Increased confidence to manage symptoms, more aware of } \\
\text { own health behaviors, eg, diet and activity level }\end{array}$ & $\begin{array}{l}\text { Better understanding and managing of } \\
\text { symptoms, more aware of healthy behaviors }\end{array}$ \\
\hline $\begin{array}{l}\text { Social and emotional } \\
\text { functioning }\end{array}$ & $\begin{array}{l}\text { More confident, empowered, improved mood, positive sense } \\
\text { of self, more connected to others, not alone, more likely to } \\
\text { talk about problems with family and friends }\end{array}$ & Enhanced self-belief \\
\hline Communicating with $\mathrm{HCPs}$ & NA & More assertive, goal-oriented consultations \\
\hline
\end{tabular}

Abbreviations: HCPs, health care practitioners; NA, not applicable. 
Table 4 Facilitators and challenges in achieving self-management goals and using TPP

\begin{tabular}{|c|c|c|}
\hline Category & Group I & Group 2 \\
\hline \multicolumn{3}{|c|}{ Facilitators in achieving self-management goals } \\
\hline $\begin{array}{l}\text { Nurse-coach } \\
\text { support }\end{array}$ & $\begin{array}{l}\text { Motivational, emotional, and goal support; links to relevant } \\
\text { information, understanding and acceptance of COPD, talking } \\
\text { through questions; help in using TPP }\end{array}$ & $\begin{array}{l}\text { Motivational, goal support; understanding COPD; talking } \\
\text { through questions; support for communicating with } \\
\text { health care professionals }\end{array}$ \\
\hline TPP & $\begin{array}{l}\text { Action plans, information about COPD and health, inspiration, } \\
\text { reminders, security, means of contacting nurse coach }\end{array}$ & $\begin{array}{l}\text { Action plans, information about COPD and health, } \\
\text { reminders, advice on self-management skills, motivational, } \\
\text { advice for communicating with health care professionals }\end{array}$ \\
\hline Social support & $\begin{array}{l}\text { Support from family and friends for goal achievement, health } \\
\text { care, company for activities, and help with IT }\end{array}$ & $\begin{array}{l}\text { Support from family and friends for goal achievement, } \\
\text { company for activities, sharing experiences, and } \\
\text { problem-solving }\end{array}$ \\
\hline Psychological factors & Feeling confident and motivated & Feeling confident and motivated \\
\hline $\begin{array}{l}\text { Self-management } \\
\text { skills }\end{array}$ & $\begin{array}{l}\text { The ability to use self-management skills and engage in health } \\
\text { behaviors }\end{array}$ & $\begin{array}{l}\text { The ability to use self-management skills and engage in } \\
\text { health behaviors }\end{array}$ \\
\hline \multicolumn{3}{|c|}{ Challenges in achieving self-management goals } \\
\hline Physical well-being & Being ill, in pain, low energy, poor eyesight & Low energy, pain, being ill \\
\hline Psychological factors & $\begin{array}{l}\text { Anxiety, low confidence, demotivation, difficulty accepting } \\
\text { limitations of COPD and so doing too much }\end{array}$ & Low mood, safety concerns, demotivation \\
\hline Other priorities & Health-related commitments and appointments, social activities & Domestic jobs taking time and energy \\
\hline Weather & Bad weather limited outside activities & Bad weather \\
\hline Social support & Lack of social support & NA \\
\hline Access to resources & Lack of exercise facilities and equipment, finance, money for fares & NA \\
\hline Behavioral factors & NA & $\begin{array}{l}\text { Trying to do too much, unhelpful triggers in the } \\
\text { environment, eg, chocolates in the house }\end{array}$ \\
\hline Housing & NA & Poor housing conditions \\
\hline \multicolumn{3}{|c|}{ Challenges to using TPP } \\
\hline IT orientation & Poor IT skills, lack of interest in computers & Poor IT skills, lack of interest in computers \\
\hline TPP design & TPP was difficult to use & TPP was difficult to use \\
\hline Individual barriers & Illness & Poor memory for passwords, pain inhibiting computer use \\
\hline
\end{tabular}

Abbreviations: NA, not applicable; TPP, The Preventive Plan.

Both groups reported other priorities that made it more difficult to work toward goals. For group 1, there were more health-related commitments, and for group 2 more domestic tasks. Bad weather limited outside activity for both groups. In addition, some in group 1 reported lack of social support and resources for activities, while for some in group 2 behavioral factors, such as trying to do too much and poor housing, presented challenges.

\section{Challenges in using TPP}

Orientation toward IT and the design of TPP were challenges for some participants in both groups. In group 1 , lack of interest in computers (one patient), poor IT skills and confidence (five) and difficulty using the site (three) made patients less willing or able to use TPP. Two who reported no benefits at all from TPP found it difficult to use, and one had poor IT skills. However, two of the highest users had poor IT skills, and one had found TPP difficult to use. In group 2, two participants reported no benefits from TPP. One found it impersonal and complicated:

I don't feel that I'm mastering it ... perhaps there's too much in there. [118, group 2]
However, similarly to group 1, of the two highest users in group 2, one had poor IT skills and both found TPP difficult to use. Barriers related to individual circumstances were ill health among group 1 and pain and poor memory for passwords among group 2 .

\section{Contact and usage}

On average, participants in group 1 accessed TPP 1.21 days/week and had 12.51 minutes of face-to-face contact time/week, 3.53 minutes of phone time/week, and 0.71 emails per week from the nurse coach (Table 5). Group 2 accessed TPP 1.32 days per week and had 18.54 minutes of face-to-face contact time/week, 2.67 minutes of phone time/week, and 1.27 emails per week. Both groups used TPP most frequently for messaging the nurse and secondly for action programs. The most frequent users were from both groups.

\section{Discussion}

In this case series of a self-management support intervention for COPD patients comprising an Internet-based healthpromotion program coupled with nurse-coach support, patients with more advanced COPD (group 1) improved 
Table 5 The Preventive Plan usage and nurse-contact time

\begin{tabular}{|c|c|c|c|c|}
\hline & Group I $(n=8)$ & Group $2(n=6)$ & Statistic & P-value \\
\hline Days TPP accessed/weeks in program, mean (SD) & I.2I (0.77) & $1.32(0.8)$ & $t=-0.244$ & 0.812 \\
\hline Nurse phone time/weeks in program, mean (SD) & $3.53(0.95)$ & $2.67(1.58)$ & $t=1.28$ & 0.225 \\
\hline Home visits/weeks in program, median (IQR) & $0.19(0.15-0.22)$ & $0.29(0.19-0.38)$ & $U=9$ & 0.052 \\
\hline Face-to-face contact time/weeks in program, mean (SD) & $|2.5|(3.9 \mid)$ & I8.54 (6.37) & $t=-2.044$ & 0.076 \\
\hline Emails sent by nurse/weeks in program, mean (SD) & $0.7 \mathrm{I}(0.2 \mathrm{I})$ & $1.27(0.23)$ & $t=-4.732$ & $<0.0005^{*}$ \\
\hline Emails received by nurse/weeks in program, mean (SD) & $0.32(0.22)$ & $0.39(0.27)$ & $t=-0.462$ & 0.653 \\
\hline Page loads (\%): messages, mean (SD) & $44.33(4.65)$ & $47.99(10.31)$ & $t=-0.81$ & 0.447 \\
\hline Page loads (\%): action programs, median (IQR) & $12.19(11.63-13.48)$ & $10.48(9.75-18.58)$ & $U=15$ & 0.282 \\
\hline Page loads (\%): health-risk assessment, mean (SD) & $3.46(1.56)$ & $3.9(1.64)$ & $t=-0.508$ & 0.621 \\
\hline Page loads (\%): personal health record, mean (SD) & $2.57(1.24)$ & $2.9(2.48)$ & $t=-0.329$ & 0.748 \\
\hline Page loads (\%): health news, mean (SD) & $1.52(1.3)$ & $1.25(0.92)$ & $t=0.43$ & 0.674 \\
\hline Page loads (\%): challenge programs, mean (SD) & $0.69(0.5)$ & $0.5 \mathrm{I}(0.7 \mathrm{I})$ & $t=0.543$ & 0.597 \\
\hline
\end{tabular}

Note: *significant at $P \leq 0.05$.

Abbreviation: TPP, The Preventive Plan.

significantly in activation, mastery, and anxiety and reported increased independence and confidence. Both this group and a second group with less advanced disease (group 2) felt better informed about COPD and reported improved physical functioning, though benefits overall were greater for patients with more advanced COPD. This occurred despite group 1 not receiving disease-specific content that was made available to group 2 and having fewer emails from the nurse coach. For group 1, the motivational, emotional, and goal support from the nurse was more important than TPP in building confidence to self-manage; some patients with clear goals used the action plans and information resources in TPP as additional support. Group 2 participants valued the nurse support, but emphasized it less than TPP.

Group 1, with more advanced disease, had lower activation at baseline and achieved more positive outcomes than group 2, despite reporting more challenges, eg, being physically unwell, anxious, and low in confidence. This is consistent with other studies where participants with poorer baseline scores achieved greater gains from self-management and pulmonary rehabilitation programs $\mathrm{s}^{35}$ and improvement in self-efficacy following an expert-patients program. ${ }^{36}$

Our work found benefits in CRQ mastery in group 1, in contrast to a previous study of a self-management program consisting of tailored sessions and telephone support from a nurse, which found no significant change in any CRQ domains or the COPD self-efficacy scale; ${ }^{37}$ this may have been a result of greater disease severity in our cohort. We also observed significant improvements in HADS - anxiety in group 1, consistent with a supported self-management intervention of initial training sessions followed by nurse home visits in a similar cohort. ${ }^{38}$ Other studies have found that patient-education programs have the potential to improve health-related quality of life within short time frames (4 months), although results are mixed. ${ }^{39,40}$

Both groups benefited from the nurse input (which was more important than TPP for group 1) and used TPP most frequently for contacting the nurse. Nurses add value to IT-based interventions by raising awareness of the need for behavior change, ${ }^{17}$ providing positive feedback and goal support ${ }^{41}$ and social and motivational support to persevere with interventions. ${ }^{17}$ In our intervention, the nurse was reassuring, and talking to her about COPD was supportive for patients. Relationships, including supportive and empathic relationships with healthcare professionals, are one of three core mechanisms for successful ehealth interventions. ${ }^{42}$

Participants varied in their use of TPP. The most frequent users were from both groups and two of the highest users had poor IT skills, so disease severity and low IT confidence and skills were not necessarily barriers where participants were motivated. Williams et $\mathrm{a}^{43}$ found that patients could use a tablet-based mobile-health application regardless of previous experience, and Cummings et $\mathrm{a}^{44}$ reported that negative previous computer experience did not prevent adoption of an online self-monitoring diary.

Patient preference may be important for engagement in Internet-based interventions. ${ }^{7}$ Not all participants were enthusiastic about using TPP: some later declared little interest in computers, and it may have differed from their expectations. Common reasons for low usage of ehealth applications are unfamiliarity with technology among elderly populations, insufficiently stimulating applications, lack of change of content over time, and low use by health care professionals. ${ }^{6,19,20}$ Factors that increase user engagement, such as refreshing content on a regular basis, sending prompts, being able to choose elective components, ${ }^{45}$ or tailoring health information 
to personal needs, ${ }^{46}$ were present in TPP, but still not all participants were engaged. Some found it complex and difficult to navigate, which was a barrier to use. High-quality user-centered design is important for uptake and use of ehealth interventions. ${ }^{43,47}$ TPP was an off-the-shelf application, previously evaluated in workplace settings in the US, ${ }^{48}$ and not validated in COPD patients. More engagement may be achieved with a dedicated application designed collaboratively with the target group and technology-design approaches combined with health models. ${ }^{49}$

\section{Implications for future research, policy, and practice}

We found that participants with the lowest levels of activation gained the most. Nurse support was particularly important for those with greater emotional and self-management support needs. This suggests the need for careful assessment of patient needs to enable efficient targeting of specialist nurse support.

Disease severity and lack of IT skills were not necessarily barriers to using the Internet-based program, but lack of motivation to use computers was. It may be helpful for patients to be introduced to an internet-based package before an intervention, in order to assess motivation and manage expectations. Costs of the intervention were nurse-coach training in use of TPP and self-management support skills and nurse-patient contact time. The mean time spent by the nurse per patient was 15.25 minutes/week for group 1 and 21 minutes/week for group 2. However, self-management interventions have the potential to be costsaving relative to usual care ${ }^{50}$ and reduce respiratory-related hospitalisations. $^{4}$

Effing et $\mathrm{a}^{51}$ provided a detailed definition of the requirements for a COPD self-management intervention. Key aspects of the definition include the need for structured personalized support, with an emphasis on motivating and engaging patients. The process requires interactions between patients and health care professionals that focus on identifying needs and motivations, eliciting goals, formulating strategies, and building confidence and competence. The definition emphasizes the importance of the relationship with the health care professional. The importance of this relationship was also apparent in our study, where the input from the nurse coach was key. There were no patients who reported that the online platform was helpful and the nurse coach was not; however, there were some patients who made little use of TPP or used it primarily to contact the nurse coach. The nurse coach was important, and for some the content and functionality of TPP provided additional benefits. Further research is needed on how and under what circumstances Internet-based support can best complement personal relationships with health care providers and how nonmedical factors impact the potential to benefit from such interventions.

\section{Limitations}

The total sample size was small, rendering numbers in each of the two groups very small. However, our aim was to explore the potential of combined ehealth support with nurse coaching in COPD, rather than to determine efficacy or establish generalizability. Results are thus presented as a contribution to generic learning in this field. For group 2, a pragmatic decision was made to provide additional structured pulmonary rehabilitation materials, and this could have impacted on outcomes. It is notable, however, that the lack of this extra resource for group 1 did not appear to be detrimental and that they achieved relatively greater benefits despite this. When measuring outcomes over time, regression to the mean can occur. Patients may join because they feel vulnerable and then naturally improve over time; however, improvement was different for the two groups. Data on patients' treatment regimens and comorbidities were not available for analysis, and these factors may have an impact on patient activation and responses to this type of intervention. A wider study incorporating factors beyond COPD severity would be needed to establish this. Resources only enabled a follow-up period of 3 months, hence it was only possible to explore immediate impact. Sustainability of outcomes from self-management support interventions is an important issue, and a longer-term follow-up would be needed to address this.

\section{Conclusion}

This case series demonstrates the feasibility of combining nurse-coach support aligned to an Internet-based health resource, TPP, in COPD. Patients with more advanced disease and lower baseline activation had the largest change in activation. The case series provides knowledge about the challenges of such an approach and the importance of the nurse-coach role.

\section{Acknowledgments}

The Preventive Plan was supplied by UK Preventive Medicine Ltd (Acre House, 11/15 William Road, London NW1 3ER, UK), and we are grateful to Stefan Wisbauer from UK Preventive Medicine for technical support in its use. 
We thank Kate Homan who conducted the qualitative interviews, Petrea Fagan who supported the nurse coach in developing the self-management support skills necessary for the study, and the patients who participated in this study. The study was funded by NHS East of England Regional Innovation Funding, and delivery of this work was supported by the Cambridge Biomedical Research Centre.

\section{Author contributions}

JF and FE conceived, sought funding for, and designed the study. FE and ER conducted the qualitative data analysis. FE, Ella M, and JF conducted the statistical analysis. JY and Emma $\mathrm{M}$ were key contributors to the interpretation of the data. All authors have been involved in drafting and revision of the manuscript for important intellectual content, and have approved the final version to be published. All authors agree to be accountable for aspects of the work. JF is the guarantor of the paper.

\section{Disclosure}

The authors report no conflicts of interest in this work.

\section{References}

1. British Lung Foundation. Chronic obstructive pulmonary disease (COPD) statistics. Available from: http://statistics.blf.org.uk/copd. Accessed January 27, 2017.

2. Yohannes AM, Baldwin RC, Connolly MJ. Depression and anxiety in elderly patients with chronic obstructive pulmonary disease. Age Ageing. 2006;35(5):457-459.

3. Toms J, Harrison K. Living with chronic lung disease and the effect of pulmonary rehabilitation. Physiotherapy. 2002;88(10):605-619.

4. Zwerink M, Brusse-Keizer M, van der Valk PD, et al. Self-management for patients with chronic obstructive pulmonary disease. Cochrane Database Syst Rev. 2014;(3):CD002990.

5. Cannon D, Buys N, Sriram KB, Sharma S, Morris N, Sun J. The effects of chronic obstructive pulmonary disease self-management interventions on improvement of quality of life in COPD patients: a meta-analysis. Respir Med. 2016;121:81-90.

6. Voncken-Brewster V, Tange H, de Vries H, Nagykaldi Z, Winkens B, van der Weijden T. A randomized controlled trial evaluating the effectiveness of a web-based, computer-tailored self-management intervention for people with or at risk for COPD. Int J Chron Obstruct Pulmon Dis. 2015;10:1061-1073.

7. Nguyen HQ, Donesky D, Reinke LF, et al. Internet-based dyspnea selfmanagement support for patients with chronic obstructive pulmonary disease. J Pain Symptom Manage. 2013;46(1):43-55.

8. Burkow TM, Vognild LK, Østengen G, et al. Internet-enabled pulmonary rehabilitation and diabetes education in group settings at home: a preliminary study of patient acceptability. BMC Med Inform Decis Mak. 2013;13:33.

9. McLean S, Nurmatov U, Liu JL, et al. Telehealthcare for chronic obstructive pulmonary disease. Cochrane Database Syst Rev. 2011;(7): CD007718.

10. Wootton R. Twenty years of telemedicine in chronic disease management: an evidence synthesis. J Telemed Telecare. 2012;18(4):211-220.

11. Lundell S, Holmner A, Rehn B, Nyberg A, Wadell K. Telehealthcare in COPD: a systematic review and meta-analysis on physical outcomes and dyspnea. Respir Med. 2015;109(1):11-26.
12. Liu F, Cai H, Tang Q, et al. Effects of an animated diagram and videobased online breathing program for dyspnea in patients with stable COPD. Patient Prefer Adherence. 2013;7:905-913.

13. Moy ML, Collins RJ, Martinez CH, et al. An Internet-mediated pedometer-based program improves health-related quality-of-life domains and daily step counts in COPD: a randomized controlled trial. Chest. 2015;148(1):128-137.

14. Barberan-Garcia A, Vogiatzis I, Solberg HS, et al. Effects and barriers to deployment of telehealth wellness programs for chronic patients across 3 European countries. Respir Med. 2014;108(4):628-637.

15. Cummings E, Robinson A, Pratt HC, et al. Pathways Home: comparing voluntary IT and non-IT users participating in a mentored selfmanagement project. Stud Health Technol Inform. 2010;160(Pt 1): 23-27.

16. Stickland M, Jourdain T, Wong EY, Rodgers WM, Jendzjowsky NG, Macdonald GF. Using telehealth technology to deliver pulmonary rehabilitation in chronic obstructive pulmonary disease patients. Can Respir J. 2011;18(4):216-220.

17. van der Weegen S, Verwey R, Spreeuwenberg M, Tange H, van der Weijden T, de Witte L. It's Life! Mobile and web-based monitoring and feedback tool embedded in primary care increases physical activity: a cluster randomized controlled trial. J Med Internet Res. 2015; 17(7):e184.

18. Zanaboni P, Lien LA, Hjalmarsen A, Wootton R. Long-term telerehabilitation of COPD patients in their homes: interim results from a pilot study in northern Norway. J Telemed Telecare. 2013;19(7): 425-429.

19. Botsis T, Hartvigsen G. Current status and future perspectives in telecare for elderly people suffering from chronic diseases. J Telemed Telecare. 2008;14(4):195-203.

20. Tabak M, Brusse-Keizer M, van der Valk P, Hermens H, VollenbroekHutten M. A telehealth program for self-management of COPD exacerbations and promotion of an active lifestyle: a pilot randomized controlled trial. Int J Chron Obstruct Pulmon Dis. 2014;9:935-944.

21. Au DH, Macaulay DS, Jarvis JL, Desai US, Birnbaum HG. Impact of a telehealth and care management program for patients with chronic obstructive pulmonary disease. Ann Am Thorac Soc. 2015;12(3): 323-331.

22. Casas A, Troosters T, Garcia-Aymerich J, et al. Integrated care prevents hospitalisations for exacerbations in COPD patients. Eur Respir J. 2006;28(1):123-130.

23. de Toledo P, Jiménez S, del Pozo F, Roca J, Alonso A, Hernandez C. Telemedicine experience for chronic care in COPD. IEEE Trans Inf Technol Biomed. 2006;10(3):567-573.

24. Lilhol PH, Hæsum LK, Hejlesen OK. Exploring user experience of a telehealth system for the Danish TeleCare North trial. Stud Health Technol Inform. 2015;210:301-305.

25. Cummings E, Turner P. Patient self-management and chronic illness: evaluating outcomes and impacts of information technology. Stud Health Technol Inform. 2009;143:229-234.

26. Hardinge M, Rutter H, Velardo C, et al. Using a mobile health application to support self-management in chronic obstructive pulmonary disease: a six-month cohort study. BMC Med Inform Decis Mak. 2015; $15: 46$.

27. Hibbard JH, Stockard J, Mahoney ER, Tusler M. Development of the Patient Activation Measure (PAM): conceptualising and measuring activation in patients and consumers. Health Serv Res. 2004;39(4 Pt 1): 1005-1026.

28. Hibbard JH, Gilburt H. Supporting People to Manage their Health: An Introduction to Patient Activation. London: King's Fund; 2014.

29. Sharma S, Wallace LM, Kosmala-Anderson J, Realpe A, Turner A. Perceptions and experiences of co-delivery model for self-management training for clinicians working with patients with long-term conditions at three healthcare economies in UK. World Hosp Health Serv. 2011;47(2):22-24.

30. Hibbard JH, Mahoney ER, Stockard J, Tusler M. Development and testing of a short form of the patient activation measure. Health Serv Res. 2005;40(6 Pt 1):1918-1930. 
31. Guyatt GH, Berman LB, Townsend M, Pugsley SO, Chambers LW. A measure of quality of life for clinical trials in chronic lung disease. Thorax. 1987;42(10):773-778.

32. Zigmond AS, Snaith RP. The Hospital Anxiety and Depression Scale. Acta Psychiatr Scand. 1983;67(6):361-370.

33. Jones RC, Wang X, Harding S, Bott J, Hyland M. Educational impact of pulmonary rehabilitation: Lung Information Needs Questionnaire. Respir Med. 2008;102(10):1439-1445.

34. Braun V, Clarke V. Using thematic analysis in psychology. Qual Res Psychol. 2006;3(2):77-101.

35. Scott AS, Baltzan MA, Fox J, Wolkove N. Success in pulmonary rehabilitation in patients with chronic obstructive pulmonary disease. Can Respir J. 2010;17(5):219-223.

36. Reeves D, Kennedy A, Fullwood C, et al. Predicting who will benefit from an Expert Patients Programme self-management course. Br J Gen Pract. 2008;58(548):198-203.

37. Bischoff EW, Akkermans R, Bourbeau J, van Weel C, Vercoulen JH, Schirmer TR. Comprehensive self management and routine monitoring in chronic obstructive pulmonary disease patients in general practice: randomised controlled trial. BMJ. 2012;345:e7642.

38. Bucknell CE, Miller G, Lloyd SM, et al. Glasgow supported selfmanagement trial (GSuST) for patients with moderate to severe COPD: randomised controlled trial. BMJ. 2012;344:e1060.

39. Bourbeau J, Julien M, Maltais F, et al. Reduction of hospital utilization in patients with chronic obstructive pulmonary disease: a diseasespecific self-management intervention. Arch Intern Med. 2003;163(5): 585-591.

40. Rice KL, Dewan N, Bloomfield HE, et al. Disease management program for chronic obstructive pulmonary disease: a randomized controlled trial. Am J Respir Crit Care Med. 2010;182(7):890-896.

41. Verwey R, van der Weegen S, Spreeuwenberg M, Tange H, van der Weijden T, de Witte L. A pilot study of a tool to stimulate physical activity in patients with COPD or type 2 diabetes in primary care. J Telemed Telecare. 2014;20(1):29-34.
42. Vassilev I, Rowsell A, Pope C, et al. Assessing the implementability of telehealth interventions for self-management support: a realist review. Implement Sci. 2015;10:59.

43. Williams V, Price J, Hardinge M, Tarassenko L, Farmer A. Using a mobile health application to support self-management in COPD: a qualitative study. Br J Gen Pract. 2014;64(624):e392-e400.

44. Cummings E, Robinson A, Pratt HC, et al. Pathways Home: Comparing voluntary IT and non-IT users participating in a mentored selfmanagement project. Stud Health Technol Inform. 2010;160(Pt 1): 23-27.

45. Voncken-Brewster V, Tange H, Moser A, Nagykaldi Z, de Vries H, van der Weijden T. Integrating a tailored e-health self-management application for chronic obstructive pulmonary disease patients into primary care: a pilot study. BMC Fam Pract. 2014;15:4.

46. Dijkstra A. Working mechanisms of computer-tailored health education: evidence from smoking cessation. Health Educ Res. 2005;20(5): 527-539.

47. Ahern DK. Challenges and opportunities of eHealth research. Am J Prev Med. 2007;32(5 Suppl):S75-S82.

48. Loeppke R, Edington DW, Bég S. Impact of the prevention plan on employee health risk reduction. Popul Health Manag. 2010;13(5): 275-284.

49. Portz JD, Miller A, Foster B, Laudeman L. Persuasive features in health information technology interventions for older adults with chronic diseases: a systematic review. Health Technol. 2016;6(2):89-99.

50. Bourbeau J, Collet JP, Schwartzman K, Ducruet T, Nault D, Bradley C. Economic benefits of self-management education in COPD. Chest. 2006;130(6):1704-1711.

51. Effing TW, Vercoulen JH, Bourbeau J, et al. Definition of a COPD selfmanagement intervention: International Expert Group consensus. Eur Respir J. 2016;48(1):46-54. 


\section{Supplementary materials}

Further detailed description of the intervention and interviewtopic guide are available from the corresponding author.

\section{The Preventive Plan}

The Preventive Plan (TPP) was a web-based program encompassing primary prevention (health promotion), secondary prevention (biometric and lab screening and early detection/ diagnosis), and tertiary prevention (chronic condition management). TPP was personalized through the uploading of personal details, including medical history, medication, family history, weight, waist measurement, current lifestyle, dietary intake, and activity levels, via a 77 item questionnaire. The application incorporated four elements, described in the following paragraphs.

Following the uploading of personal details, a personalized health-risk assessment was generated, which indicated the individual's highest risks of developing a range of conditions if no action were taken on current behavior. Risks were graded high, severe, and moderate and calculated using a variety of risk models, such as Framingham heart risk. ${ }^{1}$ Based on this a personalized prevention plan was generated to address the health risks with a range of preprogrammed recommended action programs. Focusing on health-related behaviors, such as healthy eating, alcohol consumption, exercise, and smoking cessation, these guided the user through behavior change and offered step-by-step recommendations to achieve health benefits, while encouraging users to upload individual goal achievements. The duration of these action programs was around 8 weeks. This process was personalized to the extent that the action plan addressed an identified risk for the individual, but the plans themselves were not patient-led or -formed.

\section{Table SI Interview-topic guide}

Opening discussion

- What patient hoped to gain from taking part

- Experience date

- Benefits to date

Self-management

- What self-management means to the patient

- What goals the patient has been working toward

- Goal progress and what has helped or hindered progress

TPP and nurse coach

- How TPP has contributed to goal progress

- Frequency and experience of contact with the nurse coach

- Aspects of TPP used

- Use and benefits of health-risk assessment in TPP

- Role of family/carers in supporting use of TPP

- Ease of use of TPP and hardware

Any other benefits from taking part

Abbreviation: TPP, The Preventive Plan.
TPP also incorporated information resources, including daily health-news bulletins, which could be preselected relevant to identified health risks and action plans, and a health library/tutorial facility. In addition, local uploads were installed including links to the British Lung Foundation, carer support, local resources, and a COPD self-management personal health plan that included condition-related information, symptom-monitoring, and self-management action-plan templates. Participants also received a handheld copy of this personal health plan. Access was available to health information aimed at enhancing health literacy, an important aspect of self-management. TPP enabled email communication with the nurse coach, who could also monitor when users accessed the program.

\section{Nurse-coach support}

Use of the package was integrated with support from a trained respiratory nurse via home visits, telephone, and email contact. The nurse coach assisted participants to use the website and hardware (if provided), and supported patient selfmanagement through individualized patient-led goal-setting. The role comprised user support for TPP, encouragement to use TPP, and "signposting" to other online resources for self-management through supportive email messages.

Patient-centered coaching to enhance confidence to selfmanage was also a component. This included agenda-setting, patient-led goal-setting, support for and action planning to complement TPP-generated action plans, problem-solving, goal review, verbal encouragement, and focus on past successes. Patient-led goals could range from specific healthrelated behaviors, such as healthy eating, to broader lifestyle issues, such as meeting friends. Specifically, the communication style of this role incorporated coproduction, and was distinct from that of the nurse coach's usual role as a respiratory nurse specialist, in that there was a strong emphasis on support relative to expert medical advice. For example, if a patient were to say that they thought they were having an exacerbation and ask if they should start their rescue pack, the role of the nurse coach was to educate through asking:

Why do you think you are having an exacerbation? What are your symptoms? What advice have you been given about these symptoms previously? Do you have any written instructions, such as a self-management plan?

This required specific skills distinct from medical knowledge. Education to complement information was available through TPP, with condition-specific education as appropriate to each participant's needs. 
When a participant joined the project, the nurse made an initial home visit. During this visit, she introduced the participant to TPP, provided contact details and written information about the program, collected baseline assessment data, supported the patient in completing the health-risk assessment, generated the personal prevention plan, and discussed selfmanagement priorities, patient-led goal-setting, and action plan, and agreed on follow-up contact.

During each subsequent contact, the nurse would support the participant in problem-solving and working toward their goals, agreeing on methods and timing of goal follow-up on each occasion according to patient preference. Participants were asked whether they would like the next contact to be a visit, phone call, or text. If more than 14 days had elapsed since the previous contact, then the nurse coach would text the patient inquiring what progress they were making. If no reply had been received within 3-4 days, then she would telephone. The level of support provided by the nurse coach was flexible and responsive to the patient's level of engagement with the intervention, eg, more frequent phone calls or emails to encourage contact with patients who were not readily engaging.

\section{Reference}

1. Kannel WB, Dawber TR, Kagan A, Revotskie N, Stokes J 3rd. Factors of risk in the development of coronary heart disease: six-year follow-up experience. Ann Intern Med. 1961;55(1):33-50.

\section{Publish your work in this journal}

The International Journal of COPD is an international, peer-reviewed journal of therapeutics and pharmacology focusing on concise rapid reporting of clinical studies and reviews in COPD. Special focus is given to the pathophysiological processes underlying the disease, intervention programs, patient focused education, and self management protocols.

\section{Dovepress}

This journal is indexed on PubMed Central, MedLine and CAS. The manuscript management system is completely online and includes a very quick and fair peer-review system, which is all easy to use. Visit http://www.dovepress.com/testimonials.php to read real quotes from published authors. 